\title{
Management Improvements in Libraries
}

Mr. St. John is librarian, Brooklyn Public Library.

$\mathrm{T}$ HERE ARE relatively few libraries of any type in the United States that are satisfied with the budgets on which they must operate. This will probably always be true. Consequently more and more librarians are realizing the need for careful management procedures within the library. Since librarianship is basically a development of the organization of materials, the basic elements of good administration have always been present. Its application in a practical sense, however, has been sadly lacking.

Most of us realize the serious need for more time to be devoted to the particular purpose of our individual library, whether it be service to the public, or time to consider the purchase of rare books and manuscripts to add to research collections, or to the production of bibliographies which make these collections available for use by scholars. One sound method of gaining this time within our current budget is by careful management analysis and the application of sound management improvements.

Since the basic elements of management improvement are the same in a public library as they are in the college or research library some of the experiences of the Brooklyn Public Library may be of value.

We have recently been asked by the Mayor's Committee on Management for the City of New York to submit a list of our management improvements during the years $1947-48$ through $195 \mathrm{I}-52$ and this analysis of our work provides a startling example of new services which have been made possible because of savings made possible by changes in the standard elements of our work.

An over-all cost of circulation in 1947-48 was 34 cents per volume. By I95 I-52 this cost had gone up to 38 cents per volume, or an increase of approximately I I per cent. During the same period our average salary had increased $\$ 739$ per position or 31 per cent and in addition we had been able to start a system-wide young people's department, to begin an audio-visual service, to extend considerably our community service, by sponsoring discussion groups, parent-preschool child programs and a senior citizens service. We were able to increase the number of pieces of publicity which were distributed and to absorb the additional volume of books purchased and cataloged.

The development of management improvements in the Brooklyn Public $\mathrm{Li}_{-}$ brary is a joint affair and much of the basic discussion takes place in an Advisory Board meeting. The Advisory Board is made up of the superintendents of all phases of our work performed by the professional, clerical and maintenance staffs. Since they meet weekly there is a regular opportunity of bringing to bear upon any problem, the experience and knowledge of all.

The second step is one of control and our use of control panels is described very well by Mr. Gerard Cozzarin in an article in the Library Journal for February I, 1953. 
The material for these control panels, is assembled by our statistician, and in order to make sure that we have the kind of statistics which are needed to give a clear view of the work that we are doing, we have recently completed a study of the statistics now kept. We found, as many other libraries have found, that unless such a survey is made there is danger of spending time accumulating costly statistics which are unusable. In some cases, we have found that the statistics kept are on such a broad base that they are meaningless as a control of the particular operation. In others they are so detailed that we cannot afford to keep them regularly. Consequently, we now spot check as this information is needed. Perhaps the greatest benefits have come through the installation of labor saving equipment. We can use as typical the example of our centralized registration files. These files contain normally between 750,000 and $1,000,000$ entries. For many years a fairly large staff tried to maintain these records in the regular library card catalog cases. The assistants had to stand to use the records and stretch for heavy drawers in the top rows of the catalog cases. Fatigue was a serious matter since the use of the files was constant and heavy. The annual weeding process was an almost superhuman task. A committee of supervisors was assigned the job of finding new filing equipment which would reduce fatigue and lost motion in the filing and which would permit more than one operator to work at the same files. In the spring of I95 I the members of this committee made many inspection trips to the sales rooms of commercial firms. They held conferences with salesmen at the library trying to explain our registration operation and requirements. They corresponded with the ALA and the National Office Management Association to find out if any new equipment had been used successfully for a similar operation. The doubledeck Transdex Rolldex unit with rolling chair assembly, was finally selected because it was the only one of all of the available modern filing equipment which permitted more than one operator to work on a unit simultaneously. The Transdex doubledeck files have two parallel magazines, in each of which are cross files on two levels. The lower level is stationary. The operator, on a rolling chair assembly, rolls to the record. The upper level is equipped with two rolling trays, carriages operating the length of the magazine. The records on both levels are filed in removable trays placed side by side. The operator sits in the unit facing the records and the desk, in a special rolling posture chair, which enables her to be occupied full time without moving from her station. By reducing fatigue and lost motion in filing, increased production was gained to the extent that it now takes less people to handle these files. This year our annual weeding process caused no noticeable change in the normal tempo of the division. We have been able to eliminate lifting, walking, stooping, opening and closing of the drawers. The centralization itself, which eliminated our branch files of registration, has saved an estimated 16 man years throughout the system.

In 1950 with a reorganization of our Book Order Department, the installation of standard business order forms and more efficient processing of orders resulted in a reduction of the average cost per volume of 23.4 per cent in a five-month period between February and June. In our library this saving amounted in dollars to $\$ 34, \mathrm{I} 42.90$, and enabled us to purchase 17,600 more volumes in that year. In addition, the recognition of the problems of the supplier, and the resultant action taken to make it as simple as possible for him to carry our account, made more prompt delivery possible. Now timely books appear on the 
shelves in the agencies on publication date or soon thereafter.

In another effort to reduce the amount of clerical and recording work in our service agencies so that they might have more opportunity to give professional service, we centralized completely our processing of books with the following results: an assembly line was established using the techniques of industrial production to process all books centrally. We had found that the time consumed for processing, when this work was done in the branches, averaged ten minutes per book.

In our central unit we were able to add several beneficial items to our processing, such as putting Plasti-kleer covers on each volume, and still reduce the time by 5.6 minutes per book. At the end of the first year of centralization, the average time for processing a book was 4.4 minutes. This was accomplished with relatively little capital expenditure, since the only equipment purchased were two electrical gluing machines. In the beginning, we arranged large tables in various ways, so as to allow experimentation with the flow of materials, until we learned the best arrangement to facilitate the flow for the various activities involved.

With the centralization of our processes and files, as described above, we were able to increase our activities and services. As a consequence, our circulation increased two and a half millions during the years covered by the Mayor's Report. This necessitated the employment of a great many part-time clerical assistants to handle the shelving of books and other routines. The corresponding increase in the numbers of checks to be processed for the payroll each month, presented our finance department with a very real problem. Its solution was accomplished in the same manner as described above, in relation to the selection and purchase of the Transdex equipment for cen- tral registration. Upon completion of the study, it was decided that a new type of accounting machine supplied by the $\mathrm{Na}$ tional Cash Register Company would be the answer. The first payroll was put on this in January I95 I and we soon found that the time saved by mechanization of our payroll operation, plus the combining of several operations into one, made possibe the absorption of the added volume of finance personnel. At the present time we are beginning to use this machine for our accounts payable and expect even more substantial savings. The cost of the machine has already been made up by the salary savings involved and we have reaped an additional benefit of better and clearer accounts since the recording is done in one operation.

Athough the two major units mentioned above-the accounting machine and the Roldex Transdex units were more expensive than a small library could normally afford (the Transdex unit cost \$12,832.90 and the accounting machine cost $\$ 4,625.00$ ), we have aready made them pay for themselves because of the size of our operation. However, in the case of the centralization of processing the cost was practically nothing and the savings great and continuing. Our gluing machines cost $\$ 3$ I 8.50 apiece and we estimate savings of 1 8-20 man years in the system as a result.

There are many such inexpensive mechanical devices which can be used by smaller libraries with little expense so that more time of personnel may be devoted to professional activities. One outstanding example of this has been the purchase by this library of a Sho-card machine. I think every library has the problem of handmade signs and posters. They are not only timeconsuming for the average assistant but unless there is a person on the staff with special artistic ability most of the signs cry out that they are handmade. Our inex- 
pensive equipment (it cost $\$ 631.93$ ) produced during the fiscal year I95I-52 over 3000 signs easily duplicating the same sign for each of our 50 units. It requires practically no experience to operate. We have found that the average intelligent part-time clerk can be taught to produce clean, good looking signs after a few hours of training.

Another area where practically any library can save time and overhead cost is the careful study of forms. Our printing committee meets regularly to consider approval of requests for forms. When the form is approved they determine whether or not the form should be printed or should be reproduced by multilith within the library. This committee tries to determine I) whether or not the contents of the form are needed by management or are required by law or by good financial standards; 2) whether the design of the form facilitates the use of best methods of operation and 3) whether the working methods represented by the content are the most efficient procedure. Major attention at the present time is being given to systems and procedures since we have found from experience that a request for a form presents a good opportunity to study the use of the form and the general area of activity within which the form is used. As a result, in addition to the net annual savings, of almost $\$ 4000$, which has resulted from the elimi- nation or combination of forms, and the use of multilith instead of printing, we have been able to make considerable savings in clerical costs by changes in procedure.

The examples given above are a few from a specific library. They are meant to illustrate the fact that it is possible within the limited budgets available to libraries to increase the amount of service which can be given. Businessmen are always amazed when they see the complexity of a library operation. They are inclined to question the ability of the supposedly theoretical librarian to effect a sound management program. The librarian must believe firmly that the mission of his institution is to produce quickly and accurately information at whatever level it is needed by the community which he serves. It is then a short step to the point where he realizes that he must obtain the greatest benefit from the funds available to him in attaining this mission. When he begins to analyse the procedures which have developed in his library over a period of many years, he realizes that many can be eliminated entirely since they do not contribute directly to the attainment of the mission. -

Librarians have always been noted for their cooperation. By sharing our experience in the field of management improvements we may all obtain more benefit from our budget dollar.

\section{Scholarships at the University of Illinois Library School}

A number of library and research assistantships are available to candidates for the Master's degree at the University of Illinois Library School. Students who have to their credit eighteen hours of library science or its equivalent may qualify for appointment to the staff of the University Library or the Library School, with stipends varying from $\$ 650$ to $\$ 1500$ according to the time given to work, and with waiving of tuition. Some of these involve assignment to the Demonstration Laboratory, and to activity with audio-visual materials.

Also, there are offered through the Graduate College at the University a number of fellowships open to candidates for the degree of Master of Science who are not over thirty years of age when the appointment is to be made. These grants carry stipends of $\$ 900$ for a year, and waiving of tuition. Candidates for the doctorate are eligible for second year grants, in amount of $\$ 1000$, and for third year awards of $\$ \mathrm{I} I 00$, with exemption from tuition in both cases. Students undertaking study at the Library School may apply for these benefits. Inquiries should be addressed to the associate director. 